https://doi.org/10.48009/1_iis_2005_258-264

\title{
VIRTUAL TEAM LEARNING IN ONLINE MBA EDUCATION: AN EMPIRICAL INVESTIGATION
}

\author{
Wayne Huang, Ohio University, huangw@ ohio.edu \\ Thom Luce, Ohio University, luce@ohio.edu \\ Yong Lu, Ohio University, yong.lu.1@ohio.edu
}

\begin{abstract}
Online MBA education has a great potential to meet the needs of busy professionals and reduce education costs, which is especially attractive given that funding for university education has been cut for years. Few studies have been conducted to examine how group/team learning in online education programs contributes to online learning outcomes in the research literature. This study intends to explore the correlations among virtual team learning, learning motivation, and learning outcome (satisfaction). A survey was conducted for that research purpose. Research findings reported that learning motivation was significantly correlated with learning outcome and virtual team learning was significantly correlated with learning outcome. However, virtual team learning was not significantly correlated with learning motivation. The research findings, implications and limitations are discussed.
\end{abstract}

Keywords: online MBA education, virtual team learning, learning motivation, and learning satisfaction.

\section{INTRODUCTION}

Online education program seems one potentially effective way to reduce education cost and also provide $24 \times 7$ access for many students who are residing in remote areas or are working full-time during week days. Hence, much research has been conducted on online education [e.g., 4, 5, 8, 9, 10]. While federal and state funding for education has been cut over the last years, using information technology to support higher education programs, including MBA programs, seems to be a reasonable choice for many state universities in the US.

There are some successful online university degree programs in USA, such as Phoenix University (www.phoenix.edu) that has become the largest university in US within less than 10 years, in terms of student population. However, some online degree programs have not achieved good results as expected [e.g., 1]. There are many unresolved important issues and unknown answers for unsuccessful online education programs. More empirical studies should be conducted to explore those important issues and provide solid empirical evidences for university administrators to make right and effective decisions on online education programs.

This study intends to explore online MBA education program from the perspective of virtual team learning, which has not been adequately studied in the research literature. More specifically, the research questions for the current study are as follows:

- Are online MBA program students generally satisfied with their online learning program and performance? 
- Is effective virtual team learning used in an online MBA program associated with students' perceived learning outcome?

- Is effective virtual team learning used in an online MBA program associated with students' perceived learning motivation?

- Is learning motivation associated with students' perceived learning outcome in an online MBA program?

The next section will summarize the related literature on collaborative learning models and virtual team learning. The research hypotheses follow. Section 4 describes the research methodology and provides the details of research instruments and samples. The collected data are analyzed in Section 5, and Section 6 presents the discussion and implication, followed by research limitations and future studies in Section 7.

\section{LITERATURE REVIEW}

\section{Literature Review on Relevant Learning Theories}

There are many theoretical learning models in the research literature. In general, all kinds of learning models can be categorized to two broad classifications: traditional objectivist model of learning and cognitive constructivist model of learning.

There are also some variations in the constructivist's leaning model, which includes collaborative learning model (CLM). CLM theory posits that individual learning will happen and will be further enhanced by individuals sharing learning knowledge and interacting with others. Through those sharing and interactions, individuals can be more motivated to construct new meanings of concepts and learning materials for themselves [11]. In this way, effective learning occurs and individuals can learn faster and better.

\section{Literature Review on Prior Relevant Studies}

Information technology (IT), such as groupware, can be used to support online collaborative learning in virtual teams where team members can be located in different geographical places in different time zones.

It is relatively new for universities to offer online degree programs, and thus there are a limited number of empirical studies being published on using IT to support online IS degree programs.

Flynn [6] reported that team learning without the support of IT outperformed traditional individual learning by increasing learning outcomes, enhancing learning motivation and promoting positive changes in social attitudes towards learning.

Alavi conducted an experiment to compare learning processes and outcomes of MBA students enrolled in one IS course between a traditional classroom setting and a groupware-supported synchronous setting [1]. She reported that groupware-supported synchronous virtual teams were found to achieve a higher level of perceived learning, learning skill development and learning interest than student teams without the support of groupware. 
There have been no prior empirical studies, to our knowledge, to examine impacts of asynchronous virtual teams supported by groupware on learning outcomes of a whole online MBA degree program. This current study intends to bridge the gap.

\section{RESEARCH HYPOTHESES}

Based on the above literature review on collaborative learning theory and prior relevant studies of interactions of virtual teams, online learners can be more motivated to construct new meanings of concepts and learning materials for themselves [11] and thus increase their learning outcome. Further, learning motivations and outcomes could be enhanced by collaborative learning for virtual teams supported by groupware $[1,6]$. Therefore, a research model is derived, as shown in Figure 1.

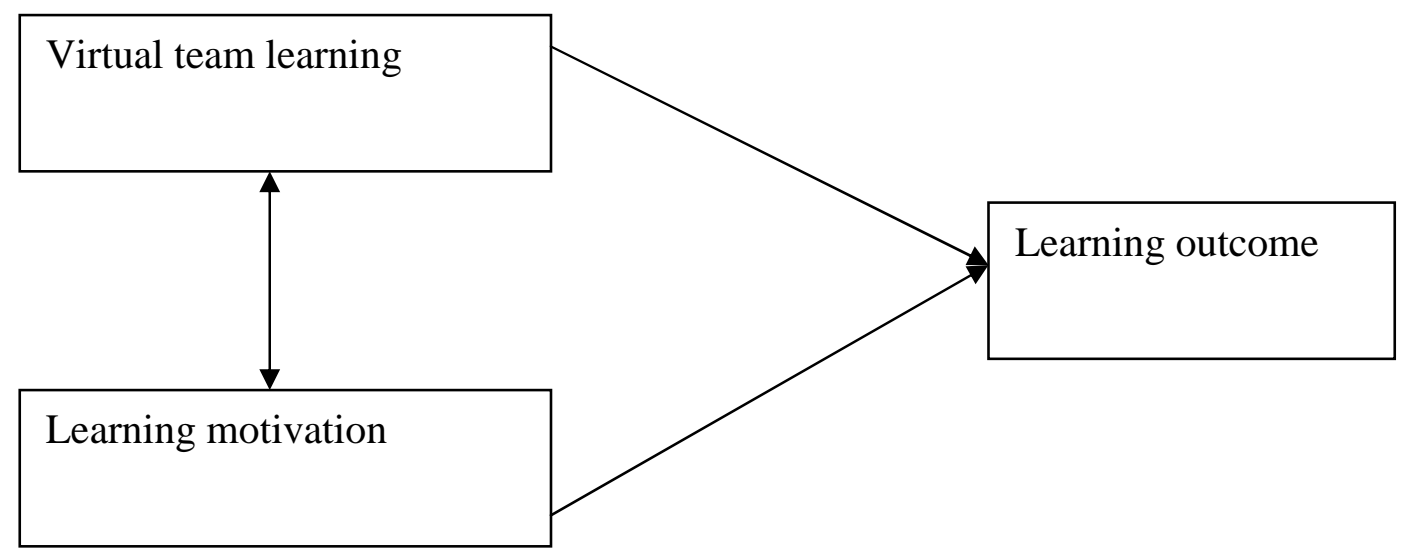

Figure 1. Research Model

Further, based on the research model, we have the following research hypotheses.

H1: Virtual team learning effectiveness will be correlated to perceived learning outcome.

$\mathrm{H} 2$ : Virtual team learning will be correlated to learning motivation.

H3: Learning motivation will be correlated to learning outcome

\section{RESEARCH METHODOLOGY}

\section{Research Design}

Unlike previous empirical studies on collaborative learning, this research examines impacts of collaborative learning of virtual teams on a whole online MBA program, rather than on a separate IS course. Therefore, an experiment research methodology was not suitable; instead, a survey research methodology was used.

All MBA students enrolled in and gradated from the online MBA Without Boundaries (MBAWB) program of Ohio University were survey subjects. Created more than 7 years ago, Ohio University's MBAWB program successfully used Problem-Based Learning Model (PBLM) and groupware (LotusNotes Domino Technology) to support virtual team learning for students 
within the US and also outside the US in locations such as in Brazil. The MBAWB program at the College of Business, Ohio University, has been ranked as one of the best accredited graduate business programs by US News and World Reports [12].

The total number of MBAWB program students is now 185. The only available contact information of the MBAWB graduates is the email addresses list that was documented when those students graduated from the program.

A cover letter was written and issued by the MBAWB director. The cover letter and questionnaire was emailed to all reachable OU MBAWB graduates, who were given about one month to fill out the questionnaire and email back the completed questionnaire.

After graduation, some graduates changed their jobs; thus, their previous email addresses were not valid anymore. Sixty-five email addresses were not valid and therefore were returned. The total number of reachable email addresses was 120 .

Among 120 valid email addresses, 35 MBAWA graduates completed the attached questionnaire and sent it back, which resulted in a response rate of $29 \%$.

Further, 6 of the 35 filled questionnaires were not usable because of missing data. Therefore, the data analysis was conducted with the 29 valid compete questionnaires.

\section{Research Instruments}

All research instruments used in the survey questionnaire were directly adopted from existing research literature.

Three research constructs were measured: learning motivations [7], perceived learning outcome (satisfaction) [3], and virtual team learning [1].

A 5-point Likert scale was used for the three constructs. In scoring the items, "strongly agree" received 5 points; "agree," 4 points; "neutral," 3 points; "disagree," 2 points; and "strongly disagree," 1 point.

\section{RESEARCH FINDINGS}

Descriptive statistics are shown in Table 1. The participants showed strong learning motivation about the online MBA program. For the three questions related to the learning motivation construct, the percentages of "strongly agree" and "agree" are 93.1\%, 93.1\% and $65.5 \%$. The participants seemed quite satisfied with the online MBA program. For the three questions related to the learning satisfaction construct, the percentages of "strongly agree" and "agree" were $85.7 \%, 89.7 \%$ and $86.2 \%$. They also showed consistent positive attitude toward virtual team learning. For the three questions related to virtual team learning, the percentages of "strongly agree" and "agree" were $96.6 \%, 100 \%$ and $79.3 \%$. 
Table 1. The Descriptive Statistics of the Three Constructs

1. Learning motivation

$\begin{array}{lllll}\text { SA } & \mathbf{A} & \mathbf{N} & \mathbf{D} & \text { SD }\end{array}$

LM1. I did my best as much as I could in the $\begin{array}{llllll}44.8 \% & 48.3 \% & 6.9 \% & 0 & 0\end{array}$

online education program

LM2. I had a great interest in the online education program.

$\begin{array}{llllll}\text { LM3. Throughout this online program, I wanted } & 20.7 \% & 44.8 \% & 31.0 \% & 3.4 \% & 0\end{array}$

to achieve better than others

2. Learning outcome (satisfaction)

LS1. I recommend this program to my colleagues.

LS2. This program is valuable to invest time and effort

LS3. I am satisfied with this online program.

3. Virtual team learning

VTL1. Team work contributed to course quality.

VTL2. Team work contributed to learning.

$\begin{array}{ccccc}44.8 \% & 48.3 \% & 6.9 \% & 0 & 0 \\ 48.3 \% & 44.8 \% & 3.4 \% & 3.4 \% & 0 \\ 20.7 \% & 44.8 \% & 31.0 \% & 3.4 \% & 0\end{array}$

VTL3. Team work was fun.

$\begin{array}{ccccc}46.4 \% & 39.3 \% & 3.6 \% & 3.6 \% & 7.1 \% \\ 27.6 \% & 62.1 \% & 3.4 \% & 3.4 \% & 3.4 \% \\ & & & & \\ 41.4 \% & 44.8 \% & 6.9 \% & 3.4 \% & 3.4 \% \\ & & & & \\ 55.2 \% & 41.4 \% & 3.4 \% & 0 & 0 \\ 58.6 \% & 41.4 \% & 0 & 0 & 0 \\ 27.6 \% & 51.7 \% & 13.8 \% & 6.9 \% & 0\end{array}$

As shown in Table 2, the means and standard deviations for the three constructs are 5.41 and 1.38 for learning motivation, 5.61 and 2.87 for learning satisfaction, 4.90 and 1.68 for virtual team learning.

Table 2. Means and Standard Deviations of the Three Constructs.

Descriptive Statistics

\begin{tabular}{|l|r|r|r|}
\hline & Mean & Std. Deviation & $\mathrm{N}$ \\
\hline learning motivation & 5.41 & 1.376 & 29 \\
learning satisfaction & 5.61 & 2.872 & 28 \\
virtual team learning & 4.90 & 1.676 & 29 \\
\hline
\end{tabular}

Internal consistency estimates of reliability (coefficient alpha) were conducted for the three constructs. In Table 3, the coefficient alpha values for learning satisfaction and virtual team learning are .94 and .81 , respectively. These values are larger than .70 , indicating satisfactory construct reliability. The coefficient alpha value for learning motivation is .26, indicating less satisfactory construct reliability. Future research should further address the learning motivation construct.

Table 3. Coefficient Alpha for Three Constructs

Constructs

Learning motivation

Learning satisfaction

Virtual team learning

\section{Coefficient alpha}

.26

.94

.81 
Table 3 presents the results of Bivariate Correlation test. The Bivariate Correlation test computers Pearson correlation and measures how variables are related. As shown in Table 4, the correlation between virtual team learning and learning satisfaction is significant, $r=.43, p<.05$. Therefore, virtual team learning is correlated to learning satisfaction. The correlation between learning motivation and learning satisfaction is significant, $r=.50, p<.01$. Learning motivation is correlated to learning satisfaction. However, the correlation between virtual team learning and learning motivation is not significant, $\mathrm{r}=.236, \mathrm{p}>.05$.

Table 4. Pearson Correlation

\section{Correlations}

\begin{tabular}{|ll|r|r|r|}
\hline & \multicolumn{1}{|c|}{$\begin{array}{c}\text { learning } \\
\text { motivation }\end{array}$} & $\begin{array}{c}\text { learning } \\
\text { satisfaction }\end{array}$ & $\begin{array}{c}\text { virtual team } \\
\text { learning }\end{array}$ \\
\hline learning motivation & Pearson Correlation & 1 & $.495^{\star \star}$ & .236 \\
& Sig. (2-tailed) &. & .007 & .218 \\
& $\mathrm{~N}$ & 29 & 28 & 29 \\
\hline learning satisfaction & Pearson Correlation & $.495^{\star \star}$ & 1 & $.430^{\star}$ \\
& Sig. (2-tailed) & .007 &. & .022 \\
& $\mathrm{~N}$ & 28 & 28 & 28 \\
\hline virtual team learning & Pearson Correlation & .236 & $.430^{\star}$ & 1 \\
& Sig. (2-tailed) & .218 & .022 &. \\
& $\mathrm{~N}$ & 29 & 28 & 29 \\
\hline
\end{tabular}

${ }^{* *}$. Correlation is significant at the 0.01 level (2-tailed).

*. Correlation is significant at the 0.05 level (2-tailed).

\section{DISCUSSION AND IMPLICATIONS}

In summary, the research findings report that

1. Virtual team learning is significantly correlated to learning satisfaction.

2. Learning motivation is significantly correlated to learning satisfaction.

3. However, there is no significant relationship found between virtual team learning and learning motivation.

One possible explanation for the unsupported hypothesis could be due to the fact that the previously validated learning motivation construct was initially designed for traditional learning rather than online learning. As a result, it may need a new instrument to measure online learning motivation rather than directly adopting the validated one from traditional learning.

Learning motivation is one important factor in influencing learning satisfaction, which is especially important to online learning where no instructors or peer classmates are physically present to a learner to motivate the learner in an online education program. Virtual team learning could be a useful means to motivate online learners in online learning. Further, virtual team learning was found to be an effective mechanism to increase online learners' satisfaction with online learning outcomes. Therefore, online learning programs should encourage the teaching pedagogy of virtual team learning in the future. 


\section{RESEARCH LIMITATIONS}

There are some research limitations in this study. First, the internal consistency estimates of reliability for learning motivation construct is less than .70. Future research should address the issue by designing a new learning motivation instrument for online learning and then validate it. Second, the sample size was 29 , although it gave an acceptable response rate of $29 \%$. Further studies could have a larger sample to further examine the research issue. Third, after a new instrument measuring online learning motivation is worked out, future studies should further examine the correlation between virtual team learning and online learning motivation.

\section{REFERENCES}

1. Alavi, M. (June 1994). Computer-Mediated Collaborative Learning: An Empirical Evaluation. MIS Quarterly, 18(2), 159-174.

2. Alavi M. \& Leidner, D. E. Research Commentary: Technology-Mediated Learning - A Call for Greater Depth and Breadth of Research. Information Systems Research, 12(1), 2001, 1-10.

3. Bailey, J.E. \& Pearson, S.W. (1983). Development of a Tool for Measuring and Analyzing Computer User Satisfaction. Management Science, 29(5), 530-545.

4. Chandler, B. (2002). Innovation in open and distance learning. Successful development of online and web-based learning. Studies in Higher Education, 27(1), 122-123.

5. Chen, S. Y. \& Paul, R. J. (2003). Editorial: individual differences in web-based instructionan overview. British Journal of Educational Technology, 34(4), 1-5.

6. Flynn, J.L. (October 1992). Cooperative learning and Gagne's events of instruction: A syncretic view. Educational Technology, 53-60.

7. Hicks, W. D., \& Klimoski, R. J. (1987). Entry into Education Outcomes: A Field Experiment, Academy of Management Journal, 30, 542-552.

8. Huang, W. \& Luce, T. (2004). Proposing an Effective Teaching Pedagogical Mode for Online MBA Education: An Exploratory Empirical Investigation. Issues in Information Systems, $V(1)$.

9. Huang, W., Yen, D., Lin, Z. X. \& Huang, J. H. (April-June 2004). How to Compete in Global Education Market Effective Conceptual Framework for Designing a Next Generation Education System. International Journal of Information Management, 12(2), 84-107.

10. Richardson, J. T. E. (2003). Approaches to studying and perceptions of academic quality in a short web-based course. British Journal of Educational Technology, 34(4), 51-63.

11. Slavin, R.E. (1990). Cooperative learning: Theory, research, and practice. Englewood Cliffs, N.J.: Prentice Hall.

12. US News and World Reports, 131(15), October 15, 2001, 62-63. 